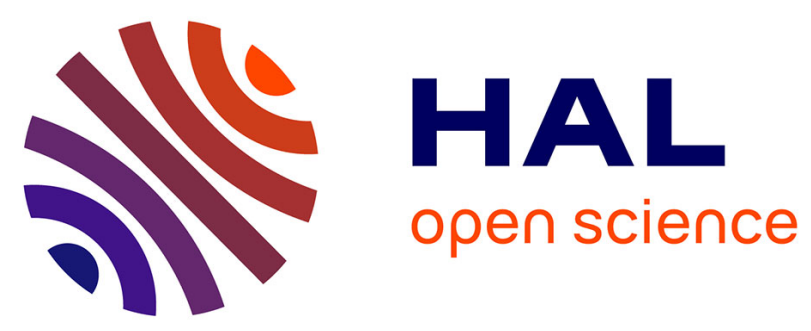

\title{
Kinome rewiring during acquired drug resistance in neuroendocrine neoplasms
}

Corinne Gerard, Marie Lagarde, Flora Poizat, Sandrine Oziel-Taieb, Vincent Garcia, Catherine Roche, Patricia Niccoli, Anne A. Barlier, David Romano

\section{- To cite this version:}

Corinne Gerard, Marie Lagarde, Flora Poizat, Sandrine Oziel-Taieb, Vincent Garcia, et al.. Kinome rewiring during acquired drug resistance in neuroendocrine neoplasms. Endocrine-Related Cancer, 2021, 28 (1), pp.39-51. 10.1530/ERC-19-0142 . hal-03164671

\section{HAL Id: hal-03164671 \\ https://hal-amu.archives-ouvertes.fr/hal-03164671}

Submitted on 10 Mar 2021

HAL is a multi-disciplinary open access archive for the deposit and dissemination of scientific research documents, whether they are published or not. The documents may come from teaching and research institutions in France or abroad, or from public or private research centers.
L'archive ouverte pluridisciplinaire HAL, est destinée au dépôt et à la diffusion de documents scientifiques de niveau recherche, publiés ou non, émanant des établissements d'enseignement et de recherche français ou étrangers, des laboratoires publics ou privés. 


\title{
Kinome rewiring during acquired drug resistance in neuroendocrine neoplasms
}

\author{
Corinne Gérard1', Marie Lagarde1', Flora Poizat22, Sandrine Oziel-Taieb², Vincent Garcia33, Catherine Roche3, \\ Patricia Niccoli', Anne Barlier1,3 and David Romano'
}

1 Aix Marseille Univ, INSERM, MMG (U1251), Marseille Medical Genetics, Marseille, France 2 Medical Oncology Department, Paoli-Calmettes Institute CoE-ENETS, Marseille, France

${ }_{3}^{3}$ Molecular Biology Laboratory, Hospital La Conception, AP-HM, Marseille, France

Correspondence should be addressed to D Romano: romanodav@yahoo.fr

\begin{abstract}
Although there is evidence of a significant rise of neuroendocrine neoplasms (NENs) incidence, current treatments are largely insufficient due to somewhat poor knowledge of these tumours. Despite showing differentiated features, NENs exhibit therapeutic resistance to most common treatments, similar to other cancers in many instances. Molecular mechanisms responsible for this resistance phenomenon are badly understood. We aimed at identifying signalling partners responsible of acquired resistance to treatments in order to develop novel therapeutic strategies. We engineered QGP-1 cells resistant to current leading treatments, the chemotherapeutic agent oxaliplatin and the mTor inhibitor everolimus. Cells were chronically exposed to the drugs and assessed for acquired resistance by viability assay. We used microarray-based kinomics to obtain highthroughput kinase activity profiles from drug sensitive vs resistant cells and identified 'hit' kinases hyperactivated in drug-resistant cells, including kinases from FGFR family, cyclin-dependant kinases and PKCs in oxaliplatin-resistant (R-Ox) QGP-1 cells. We then validated these 'hit' kinases and observed that ERK signalling is specifically enhanced in QGP-1 R-Ox cells. Finally, we assessed drug-resistant cells sensitivity to pharmacological inhibition of 'hit' kinases or their signalling partners. We found that FGFR inhibition markedly decreased ERK signalling and cell viability in QGP-1 R-Ox cells. These results suggest that the FGFR/ERK axis is hyperactivated in response to oxaliplatin-based chemotherapeutic strategy. Thus, this sensitive approach, based on the study of kinome activity, allows identifying potential candidates involved in drug resistance in NENs and may be used to broadly investigate markers of NENs therapeutic response.
\end{abstract}

\section{Introduction}

Neuroendocrine neoplasms (NENs) (comprising welldifferentiated NENs ((G1 to G3) and poorly differentiated NECs (Inzani et al. 2018)) are a heterogeneous group of malignancies with various clinical presentations and evolution. These neoplasms are characterized by a variable behaviour, from indolent to highly aggressive, and a large number of these tumors have a prolonged clinical course (Ohmoto et al. 2017). Prognosis and treatment are mainly dictated by histological grade based on the Ki-67 proliferation index (Kulke 2017). The current treatments of NENs consist of a multimodal approach. If feasible, surgical resection remains the first option and 
can result in a complete cure of the disease. However, the large majority of newly diagnosed patients presents with metastasis, requiring an effective systemic treatment to extend survival (Aristizabal Prada \& Auernhammer 2018).

The advent of powerful high-throughput techniques, such as next-generation sequencing, allowed a deeper, unbiased exploration of tumour specimens, leading to progressive accumulation of further knowledge on the mechanisms that drive progression towards malignancy. In the last decade, many efforts contributed to the discovery of a number of deregulated genes related to NENs pathogenesis and progression, some of them also representing potentially druggable molecular targets (Jiao et al. 2011, Scarpa et al. 2017). For instance, the PI3K/ AKT/mTor pathway has been highlighted as a key player in the development of NENs, particularly from pancreas (Missiaglia et al. 2010, Qian et al. 2013). In this context, the mTor inhibitor everolimus has been largely studied in NENs and approved by both Food and Drug Agency (FDA) and European Medical Agency (EMA) for patients with advanced well-differentiated pancreatic NENs. However, comprehensive clinical studies did not conclude to any improvement of overall survival of NENs patients treated with everolimus despite a significant increase in progression free survival (Pavel et al. 2011, Yao et al. 2016).

Cytotoxic agents are recommended in the ENETS consensus Guidelines for patients with poorly differentiated neuroendocrine carcinomas (NECs), as well as for those with well-differentiated NENs (G1 to G3) with bulky, rapidly progressive and/or after failure of other therapies (Pavel et al. 2016). Among chemotherapeutic options, oxaliplatin-based chemotherapies have been evaluated in phase II clinical trials and retrospective studies in different centres (Bajetta et al. 2007, Dussol et al. 2015, Spada et al. 2016). These studies suggest that oxaliplatin-based cytotoxic strategies could be active with a manageable safety profile in NENs. FOLFOX combination was recently evaluated for its efficacy and tolerability in patients with advanced grade $1 / 2$ NENs (Faure et al. 2017) and in NECs (Hadoux et al. 2015). In our ENETS centre, following Faure et al. retrospective study, we observed that good responders to FOLFOX treatment showed disease progression after a median chemotherapy break of 10 months and that $75 \%$ of these patients exhibited therapeutic resistance to FOLFOX rechallenge (OzielTaieb S, unpublished results).

NENs traditional treatments usually induce tumour stabilization for limited length of time. Thus, there is an urgent need to develop novel approaches to overcome treatment-related resistance in patients with advanced and progressive NENs. Despite growing evidences that poorly differentiated NENs may harbour mutations commonly observed in pancreatic or colorectal adenocarcinomas (Klempner et al. 2016, Girardi et al. 2017, Konukiewitz et al. 2018, Simbolo et al. 2018, Shamir et al. 2019), whole-genome integrated analysis confirmed previous observations that NENs display few, if any, actionable mutations providing compelling rationale for targeted therapies (Scarpa et al. 2017, Kawasaki et al. 2018).

In recent years, much attention focused on identifying key cellular signal transduction pathways that are abnormally activated or deactivated in cancer cells. These pathways involve cascades of kinases that ultimately impact on gene transcription. In NENs, several studies hinted a role for tyrosine kinases receptors (VEGFR, EGFR, PDGFR), Src family kinases and PI3K/AKT/mTor pathway as potential therapeutic targets (Di Florio et al. 2011, Corbo et al. 2012, Kidd et al. 2013, Qian et al. 2013, Nölting et al. 2017). Adaptive resistance to treatments uses existing homeostatic feed-forward and feedback loops to rapidly rewire signalling networks (Wilson et al. 2018). This has been observed in NENs with an upregulation of AKT signalling pathway caused by everolimus, leading to loss of feedback loop from mTOR (Zitzmann et al. 2010, Passacantilli et al. 2014, Mohamed et al. 2017). Platinum-based chemotherapies also induce signalling pathways activation, such as DNA damage response, checkpoint kinases and MAPK proteins (Riddell \& Lippard 2018).

In order to acquire in-depth knowledge of kinomewide networks and their perturbations during drug resistance acquisition in NENs, we used a microarraybased kinomics approach to investigate the role of specific kinases in oxaliplatin-based chemotherapeutic resistance. We established kinomics profiling of NENs cell lines and compared them to tumor samples to functionally validate them as accurate preclinical models to study kinases behaviour in NENs in a drug response context. In addition, comparative analysis between chemo-resistant vs -sensitive NENs cells identified hyperactivated kinases as new druggable candidates to sensitize NENs cells in relapse from first-line treatments.

\section{Materials and methods}

\section{Patients}

The present study was approved by the Ethics Committee of the Aix-Marseille University (Aix-Marseille, France) and 
informed consent was obtained from each patient. Nine patients with NEN and one patient with NEC tumour were included in the study (Table 1). All the patients were bearing tumour requiring surgical removal. All patients, excepted patient from who was extracted tumour 10, were naïve of antitumor treatment before surgery. The only criterion for tumour selection was their identification as primary NEN by pathological analysis. Determination of Ki67 and proliferation index allowed grade classification (WHO 2019 classification) (Table 1). Adenocarcinoma samples used in Supplementary Figures (see section on supplementary materials given at the end of this article) were from patients as followed: Colon (C), a 71-year-old male, TNM stage pT4N1M1 (IV); Lung (L), a 72-year-old male, TNM stage pT3N1M0 (IIIA); Breast (B), a 58-year-old female, TNM stage pT2N1M0 (IIB).

\section{Cell lines and establishment of drug-resistant cells}

QGP-1 and BON-1, two validated human neuroendocrine cell line models, were used in this study (Hofving etal. 2018). Cells were cultured in an atmosphere of 95\% humidity and $5 \% \mathrm{CO} 2$ at $37^{\circ} \mathrm{C}$. BON-1, a gift from Dr Corinne Bousquet (CRCT, Toulouse, France), and QGP-1, acquired from Japanese Collection of Research Bioresources Cell Bank (JCRB), were, respectively, maintained in DMEM:Ham's F12 (1:1) and RPMI-1640 supplemented with 10\% defined Foetal Bovine Serum Gold (PAA, France), penicillin (100 $\mathrm{U} / \mathrm{mL})$ and streptomycin $(100 \mu \mathrm{g} / \mathrm{mL})$. To establish drugresistant QGP-1 cells, QGP-1 cells were chronically treated with either a fixed everolimus concentration $\left(10^{-8} \mathrm{M}\right)$ during 3 months or an increasing dose of oxaliplatin (up to $2 \mu \mathrm{M}$ ) during 18 months. We used these protocols to reach the physiological circulating concentration of drugs detected in treated patients (Graham et al. 2000, Budde et al. 2016). Drug resistance was determined by cell viability assay (see subsequently). Resistant cells were then maintained in respective medium supplemented with the drugs. Total cellular extracts from pancreatic adenocarcinoma cell lines (Bx-PC3 and MiaPaca) were kindly provided by Dr Eric Mas (CRO2, U911 INSERM-AixMarseille University, France).

\section{Drugs and reagents}

The mTor inhibitor everolimus was provided by Novartis (Novartis AG, Basel, Switzerland); oxaliplatin, pan-FGFR inhibitor LY2874455 and MEK inhibitor trametinib were purchased from Selleckchem (Euromedex, France).

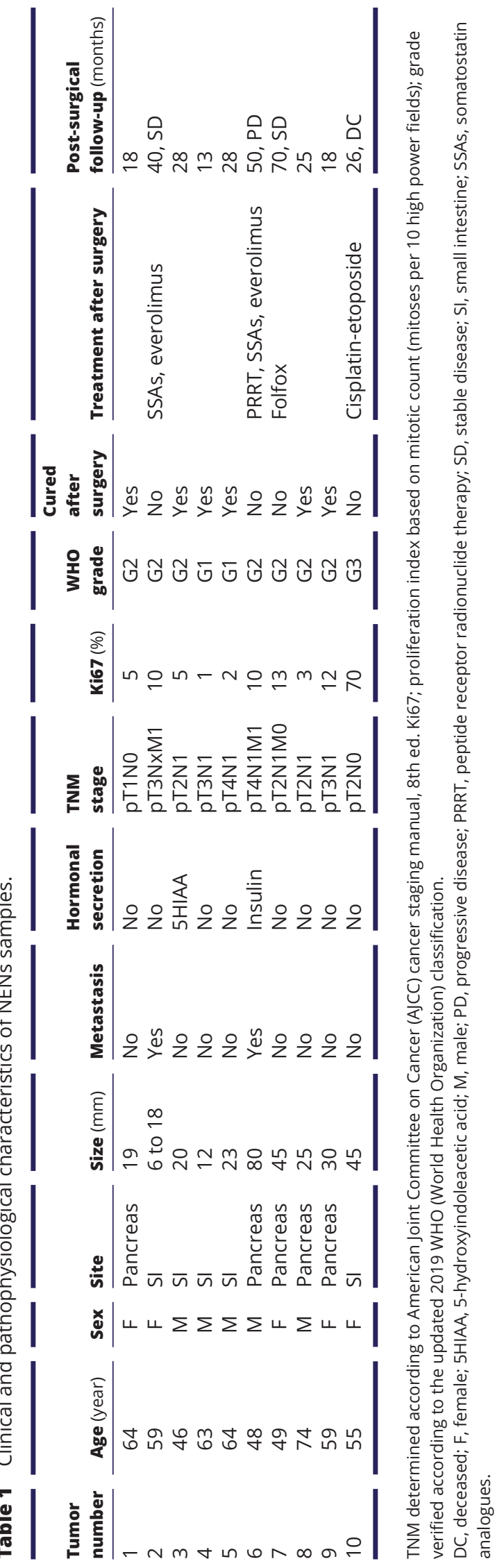


oxaliplatin was solubilized in water at $12.5 \times 10^{-3} \mathrm{M}$ and stored at $4^{\circ} \mathrm{C}$. Stock solutions of $10^{-2} \mathrm{M}$ for everolimus, LY2874455 and trametinib were prepared in DMSO and stored at $-80^{\circ} \mathrm{C}$. Serial dilutions to obtain working concentrations were done directly in the culture medium (corresponding final DMSO dilutions were from $10^{3}$ to $10^{9}$ fold). PamChip microarrays and assay reagents were purchased from PamGene International B.V. (Hertogenbosch, The Netherlands). Total extracted protein concentrations from cell and tissue samples were assayed using Pierce ${ }^{\mathrm{TM}}$ BCA Protein Assay Kit (Thermo Fischer Scientific).

\section{Kinomics assay}

Kinase activity profiling was performed using PamStation ${ }^{\circledR} 12$ (PamGene). Cell and tumor samples were lysed at $4^{\circ} \mathrm{C}$ using Mammalian Protein Extraction Reagent (M-PER), phosphatase and protease inhibitors (Thermo Fischer Scientific). Next, lysates were centrifuged $(20 \mathrm{~min}$ at $10,000 \mathrm{~g})$. In total, $5 \mu \mathrm{g}$ or $1 \mu \mathrm{g}$ of total protein lysates were loaded onto the appropriate PamChip Array for PTK (protein tyrosine kinome) or STK (serine/threonine kinome), respectively, according to PamGene's protocol, then incubated in kinase buffer and studied on PamStation $\otimes_{12}$. The PamChip peptide microarray system analyses 144 individual tyrosine phosphorylatable peptides or 144 serine and threonine phosphorylatable peptides imprinted and immobilized in a 3D format to assess kinomic activity in cell. FITC conjugated antibodies were used for visualization during and after lysates were pumped through the array. Peptide phosphorylation signal was captured via a computercontrolled charge-coupled device (CCD) allowing realtime recording of the reaction kinetics. After washing of the arrays, fluorescence was detected at different exposure times (20, 50, 100 and $200 \mathrm{~ms})$. Kinomic profiling was analysed using the Evolve ${ }^{\circledR}$ (PamGene) software for initial sample and array processing as well as image capture and BioNavigator ${ }^{\circledR}$ (PamGene) for raw data transformation into kinetic (initial velocity) and steady state (postwash) values.

\section{Genomic and transcriptomic analysis}

DNA and mRNA were extracted from QGP-1 parental and drug-resistant cells using QiaAmp DNA mini kit and RNeasy Plus mini kit, respectively (Qiagen), following manufacturer's instructions. Cell lines genetic analysis was achieved by targeted next-generation sequencing (NGS) of DNA. The coding exons and flanking regions of genes were sequenced using the Custom QIAseq targeted DNA Panel (Qiagen) following manufacturer's instructions. These genes were chosen according to (i) the most recent publications on whole genome sequencing or exome sequencing of GEP-NENs, (ii) kinomic data obtained from NEN cell lines in the present studies (Supplementary Table 1). The QIAseq targeted DNA panel utilizes unique molecular identifiers (UMI) to detect low frequency variants (Xu et al. 2017). A total of $100 \mathrm{ng}$ of genomic DNA were used for libraries construction and target enrichment. Libraries were quantified using Agilent High Sensitivity DNA Kit (Agilent), then sequenced using 150 bp paired-end sequencing procedure on Illumina Miseq (Illumina Evry, France). Data were analysed using QIAseq targeted sequencing data analysis pipeline, available on Qiagen web site (http://www.qiagen.com/us/shop/genesand-pathways/data-analysis-center-overwiew-page/). In silico analysis of variants was performed using Polyphen2 (http://genetics.bwh.harvard.edu), UMD-predictor®, and ALAMUT 2.2.0 (http://www.interactive-biosoftware. $\mathrm{com} /$ ) softwares. Quantification of target mRNA was achieved by Nanostring nCounter® technology using the 'pan-cancer panel pathway' including over 700 targets. Samples were processed in triplicates and data presented are means \pm s.E.M. of one of the representative biological triplicates. Data analysis was performed using nSolver ${ }^{\mathrm{TM}}$ 4.0 software (Supplementary Table 2).

\section{Protein extraction and Western blotting}

QGP-1 cells were seeded into six-well plates $\left(0.35 \times 10^{6}\right.$ cells/well). After $72 \mathrm{~h}$ in culture, cells were treated with the different pharmacological agents as indicated in the figure legends. Cells were then solubilized as indicated above and $10 \mu \mathrm{g}$ of extracted proteins were separated on SDS-PAGE and transferred onto PVDF membrane (Perkin Elmer). The following primary antibodies were used for immunodetection: poly- and monoclonal rabbit antibodies against Phospho (Tyr653/654)-FGF Receptor (\#3471), FGF Receptor 1 (\#3472), Phospho(Ser473)-Akt (\#9271), Phospho-MAPK/CDK Substrates (clone 34B2, \#2325), Phospho-(Ser/Thr) PKC Substrate (\#2261) and PARP (\#9542) were from Cell Signalling Technology; mouse monoclonal Anti-MAP Kinase, Activated (Diphosphorylated ERK-1\&2) antibody (M8159) and rabbit polyclonal Anti-MAP Kinase (ERK-1, ERK-2) antibody (M5670) were from Sigma (Sigma-Aldrich); mouse monoclonal antibodies against cyclin D1 (clone 
A-12, sc-8396) and total Akt1 (sc-135829) were from Santa Cruz Biotechnology (Clinisciences, France); mouse MAB against GAPDH (clone C65, \#MAB374) was from Merck (MerckMillipore). As secondary antibodies, an anti-mouse (\#7076) or rabbit (\#7074) IgG HRP-linked antibody from Cell Signalling Technology was used. Blots were developed with the SuperSignal ${ }^{\mathrm{TM}}$ West Pico PLUS Chemiluminescent Substrate (ThermoFisher Scientific). Chemiluminescent signals were detected using a charge coupled device camera using Syngene software (Gbox, Ozyme, France). Signal vs background was quantified using NIH Image J software. Results presented in figures are representative experiments of at least $n=3$ repeats. Quantifications were expressed in ratio \pm s.E.M.

\section{Cell viability}

QGP-1 and BON-1 cells were seeded into 24-well plates at $8 \times 10^{4}$ and $4 \times 10^{4}$ cells/well, respectively. After 24 $\mathrm{h}$ in culture, cells were treated or not with the different pharmacological agents for 4-7 days as indicated in the figure legends. Cell viability was assayed by a CellTiterGlo® luminescent assay (Promega) according to the manufacturer's protocol. Each assay was performed in triplicate. Results were expressed as percentages of the value for respective control cells and presented as means \pm s.E.M. A representative experiment of at least three independent experiments was given. Respective IC50 of pharmacological agents was determined using GraphPad curve fitting.

\section{Statistical analysis}

For kinomics study, image analysis and signal quantification were performed using the BioNavigator ${ }^{\circledR}$ software (PamGene). Peptides that showed kinetics (increase in signal intensity in time) were preselected ('QC list') and log transformed. For each peptide, the comparisons between sensitive and resistant cells were performed using ANOVA. Kinexus Kinase Predictor was interrogated by BioNavigator software to determine putative upstream kinases from phosphorylated peptides datasets. For all other statistical analysis, we used Student's t-test.

\section{Results}

\section{Kinomics profiling of NENs cell lines and tumor samples}

We used the GEP-NENs cell lines QGP-1 and BON-1 to compare their kinomic profiles with those from NEN tumour samples described in Table 1. Both serine/ threonine (Ser/Thr)-kinase and tyrosine (Tyr)-kinase activities were assessed using microarray-based kinomics on the PamStation ${ }^{\circledR} 12$ as indicated in the 'Materials and methods' section. We used an unbiased sample sorting based on column mean signal and observed a higher number of strongly tyrosine-phosphorylated peptides in the NEC sample (tumour 10 (G3), Fig. 1A). In this context, QGP-1 cells displayed a Tyr-kinase kinomic profile
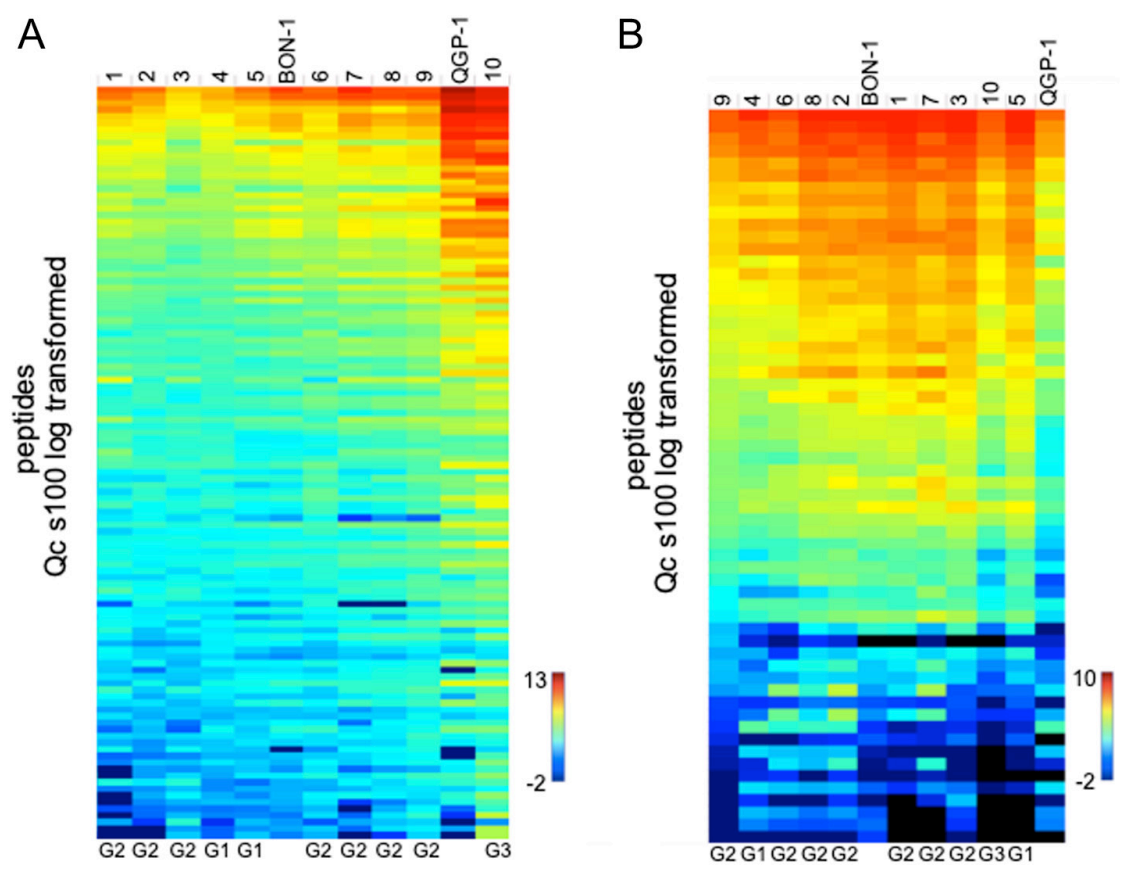

Figure 1

Basal kinase activity profiles from QGP-1, BON-1 and NENs samples. 5 and $1 \mu \mathrm{g}$ of total protein extracts from QGP-1, BON-1 cells and patients' tumour samples were analysed using Pamgene assay for tyrosine- and serine/threonine-kinases activities, respectively. Data were processed through BioNavigator software and samples were ranked according to their overall average signal. Data are shown as heatmaps of log-transformed normalized signal intensities of Tyr- (A) and Ser-/Thr- (B) phosphorylated peptides, representing peptides of the 'QC list' and sorted from high (red) to low (blue) signal intensity. S100 is a quantitation type representing the measured signal at 100 times the slope calculated using multiple exposure times. Top: number of tumour and cell lines; bottom: WHO grade. Representative experiments of $n=3$ repeats are shown. 
clustering with tumour 10, whereas Tyr-kinase activities in BON-1 cells were closer to G1/2 tumour samples (Fig. 1A). On the other hand, BON-1 cells presented with globally more Ser-/Thr-phosphorylated peptides and, unlike QGP-1 cells, bundled with most of NEN samples (Fig. 1B).

We then compared kinomic profiles from NEN samples with adenocarcinoma (AdK) samples from lung, breast and colon (Supplementary Fig. 1A and B). We observed that NENs display lower Tyr- (Supplementary Fig. 1A) and higher Ser/Thr- (Supplementary Fig. 1B) kinome activity profiles than Adk. These data suggested that NENs hold a signature in terms of kinase activity profiles that clearly distinguishes them from other more common tumours. Similarly, QGP-1 and BON-1 displayed a clear higher Ser/Thr-kinome activity when compared to Adk samples (Supplementary Fig. 1D). Interestingly, we observed that QGP-1 Tyr-kinome profile was similar to those from AdK samples (Supplementary Fig. 1C), confirming an overall kinome activity closer to more aggressive tumoral phenotype. Considering that previous works showed distinct molecular aberrations between pancreatic NEN and pancreatic ductal adenocarcinoma (PDAC) samples (Jiao et al. 2011), we compared kinomic profiles from pancreatic NEN cell lines to well-characterized PDAC cell lines to assess whether such difference was maintained in these models at the level of pan-kinase activity. QGP-1 and BON-1 displayed lower Tyr-kinase activity profiles than
MiaPaca and BxPC3 (Supplementary Fig. 1E), whereas Ser-/Thr-kinase activity profiles were significantly higher in BON-1 (Supplementary Fig. 1F). Altogether, these kinome profiling data reveal that GEP-NEN cell lines are molecularly related to NEN samples.

\section{Establishment of drug-resistant NENs cell lines}

In order to assess signalling mechanisms involved in NENs cells therapeutic resistance, we engineered NENs cell lines resistant to current first-line treatments, the mTor inhibitor everolimus and the chemotherapeutic agent oxaliplatin. First, we established their differential sensitivity to the drugs by cell viability assay. QGP-1 viability was decreased by $44 \pm 11 \%(n=4)$ and $95 \pm 2 \%(n=6)$ following treatments with either everolimus (IC50 $=0.96 \pm 0.53 \mathrm{nM}$ ) or oxaliplatin (IC50 $=0.29 \pm 0.06 \mu \mathrm{M}$ ), respectively (Fig. $2 \mathrm{~A}$ and B). BON-1 cells were sensitive to everolimus only (75 $\pm 5 \%$ decrease of cell viability, IC $50=0.36 \pm 0.22 \mathrm{nM}$, $n=4)$ and not to oxaliplatin (IC50 $=2.1 \pm 0.2 \mu \mathrm{M}, n=4$ ) (Supplementary Fig. 2A and B). Considering the lack of sensitivity of BON-1 cells to oxaliplatin, we focused our further study on comparing mechanisms of drug resistance in QGP-1 cells. We then chronically treated QGP-1 cells with everolimus or oxaliplatin as indicated in the 'Materials and methods' section to obtain drug-resistant QGP-1 cells. Acquisition of drug resistance was tested by
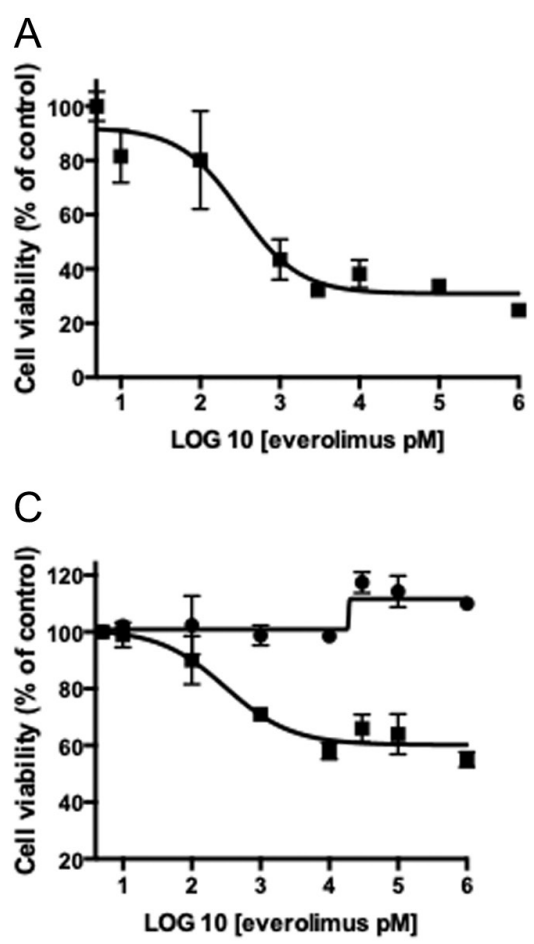
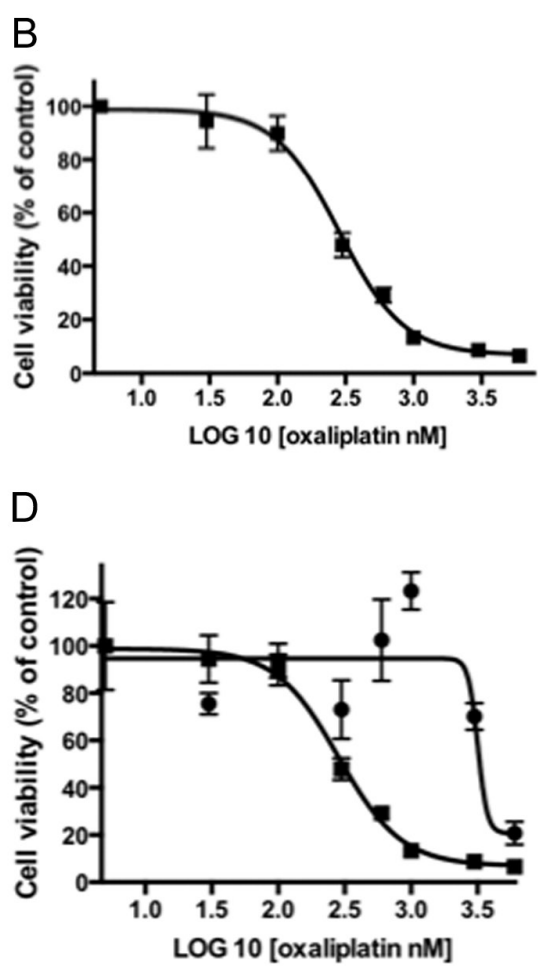

\section{Figure 2}

QGP-1 sensitivity to treatments and establishment of drug-resistant QGP-1 cells. After $24 \mathrm{~h}$ in culture, QGP-1 cells were treated for 7 days with increasing concentrations of (A) everolimus or (B) oxaliplatin as indicated. After chronic exposure of QGP-1 cells to the drugs as described in the 'Materials and methods' section, cells were assessed for (C) everolimus (QGP-1 RR, circles) or (D) oxaliplatin (QGP-1 R-Ox, circles) resistance in comparison to parental QGP-1 cells (squares). Cell viability was assessed using Cell Titer Glo assay. Representative experiments are given: (A) IC50 $=0.31 \mathrm{nM}$, maximal inhibition $=69.1 \%$; (B) IC50 $=0.28 \mu \mathrm{M}$, maximal inhibition $=93 \%$; (C) QGP-1 IC50 = $0.31 \mathrm{nM}$, maximal inhibition $=39.8 \%$ (squares); (D) QGP-1 IC50 =0.28 $\mu \mathrm{M}$ (squares), QGP-1 R-Ox IC50 = $3.18 \mu \mathrm{M}$ (circles). 

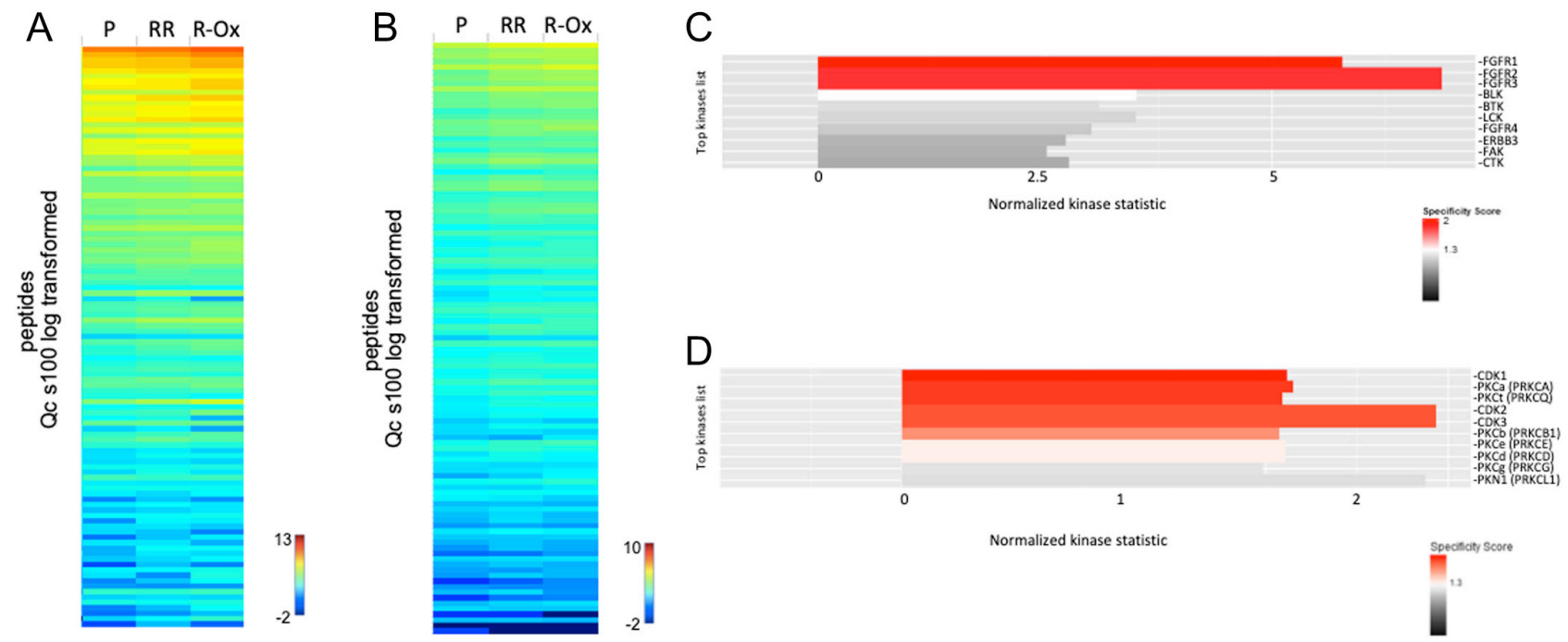

$\mid$

Normalized kinase statistic

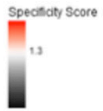

Figure 3

Hyperactivated kinases in QGP-1 R-Ox cells. 5 and $1 \mu \mathrm{g}$ of total protein extracts from QGP-1 parental (P), everolimus-resistant (RR) and oxaliplatinresistant (R-Ox) cells were analysed using Pamgene assay for tyrosine- and serine/threonine-kinases activity, respectively. Data are shown as heatmaps of log-transformed normalized signal intensities of Tyr- (A) and Ser-/Thr- (B) phosphorylated peptides, representing peptides of the 'QC list' and sorted from high (red) to low (blue) signal intensity. S100 is a quantitation type representing the measured signal at 100 times the slope calculated using multiple exposure times. Data were processed through BioNavigator software to compare kinase activities between parental vs drug-resistant cells. Kinases were obtained from Kinexus Kinase Predictor. The top ten active (C) tyrosine- and (D) serine/threonine-kinases in QGP-1 R-Ox cells vs parental are indicated in the figure. A positive Normalized Kinase Statistic value indicates a kinase activity higher for QGP-1 R-Ox cells than parental ones. The specificity score indicates the specificity of the 'Normalized Kinase Statistic' in terms of the set of peptides used for the corresponding kinase. The higher the score, the less likely it is that observed 'Normalized Kinase Statististic' could have been obtained using a random set of peptides from the data set. Specificity scores typically range from 1.3 (low) to 2.5 (high). Representative experiments of $n=3$ repeats are shown.

a short-time (7 days) dose response effect of everolimus or oxaliplatin on chronically treated cells. We observed QGP-1 cells continually exposed to $10^{-8} \mathrm{M}$ everolimus were not sensitive to the inhibitor at concentrations up to $1 \mu \mathrm{M}$ (Fig. 2C), deeming them as everolimus resistant (QGP-RR). Similarly, we observed that, after long exposure to increasing concentrations of oxaliplatin, QGP-1 cells were scarcely sensitive to a 7 days treatment with oxaliplatin and IC50 was shifted to a nearly ten-fold higher oxaliplatin concentration $(2.68 \pm 0.42 \mu \mathrm{M}, n=4, P<0.001$ vs parental QGP-1) (Fig. 2D). These data suggest we reliably obtained oxaliplatin-resistant cells (QGP-1 R-Ox).

\section{Identification of hyperactivated kinases in drug- resistant QGP-1 cells by comparative analysis of kinome profiles}

To identify kinases hyperactivated in drug-resistant QGP-1 cells, we compared kinomic profiles from parental QGP-1 cells vs QGP-1 RR and R-Ox (Fig. 3A and B). Overall kinases profiles in drug-resistant cells are similar to parental ones, suggesting that kinase activity rearrangements in drug-resistant cells are narrowed to relatively few kinases. However, both Tyr- (Fig. 3A) and Ser/Thr-kinases
(Fig. 3B) activities displayed different patterns on subsets of phosphorylated peptides. These differences were statistically significant to extract hyperactivated upstream kinases in R-Ox cells only.

Altered peptide lists were cross-compared for recurrent upstream kinases using kinexus kinase predictor database. We found fibroblast growth factor receptor family (FGFR1, 2 and 3), cyclin-dependent kinases (CDK) 1/2/3, classical and novel protein kinases C (PKC) significantly hyperactivated in QGP-1 R-Ox compared to parental ones (Fig. 3C and D). No kinases were significantly detected as hyperactivated in QGP-1 RR (not shown), suggesting that everolimus resistance is not associated with specific kinase deregulation.

We then validated 'hit' kinases by western blotting using specific antibodies against active phosphorylated forms of these kinases. We detected significant increases in FGFR (6.4 \pm 0.3 -fold vs parental cells, $n=3)$ and downstream effector ERK ( $2.5 \pm 0.1$-fold vs parental cells, $n=3$ ) phosphorylation in QGP-1 R-Ox only (Fig. 4A and B). Specific hyperactivation of EkRK and PKC kinases was also observed using an antibody against phosphorylated substrates of these kinase families (Supplementary Fig. 3A and B). Interestingly, cyclin D1 expression was also increased 
A

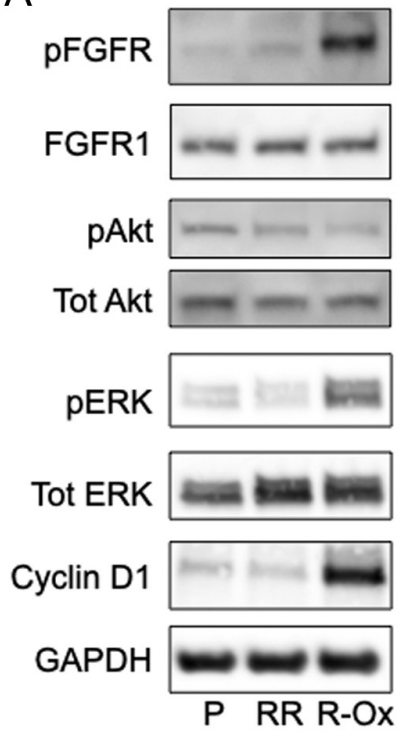

B

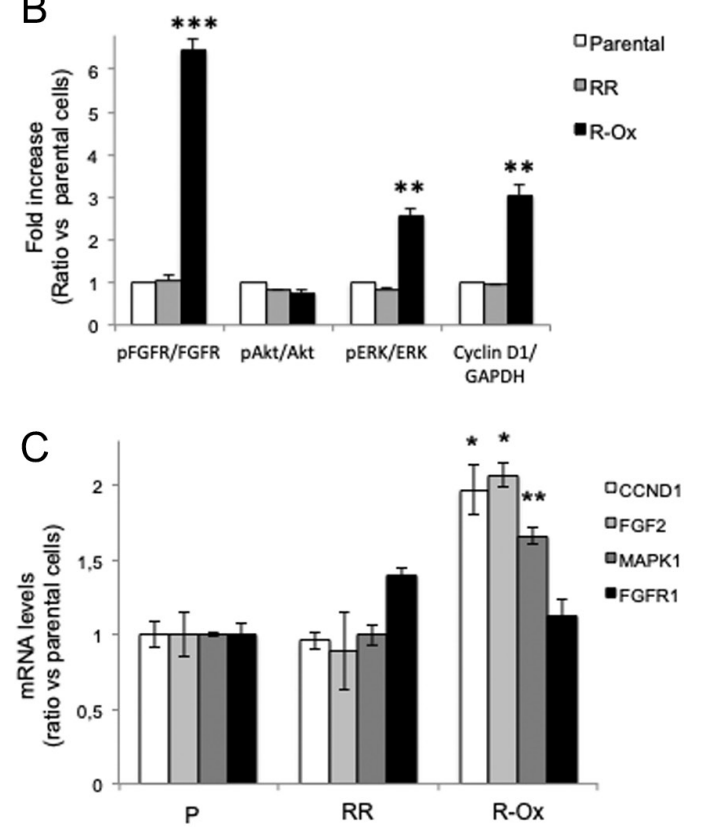

\section{Figure 4}

Validation of 'hit' kinases activities by Western blot. (A) $10 \mu \mathrm{g}$ of protein extracts from QGP-1 parental $(P)$, everolimus-(RR) and oxaliplatin(R-Ox) resistant cells were separated by SDS/PAGE and immunoprobed using primary antibodies against indicated proteins. Membranes blotted with antibodies against phosphorylated proteins (pFGFR, pAkt and pERK) were then stripped and re-probed using primary antibodies against total proteins. (B) Quantification of phosphorylated/ total proteins and cyclin D1/GAPDH. Results are expressed as ratio vs respective control in parental cells. Means \pm S.E.M. of $n=3$ experiments are shown. (C) mRNA were extracted and quantified as indicated in the 'Materials and methods' section. mRNA levels of FGFR1, CCND1, FGF2 and MAPK1 genes in parental (P), everolimus resistant (RR) and oxaliplatin resistant (R-Ox) QGP-1 cells are shown. Results are represented as ratio vs respective control in parental cells. $\star P<0.05 ; * \star P<0.01 ; * \star \star P P<0.001$.
(3.05 \pm 0.2 fold vs parental cells, $n=3$ ) in QGP-1 R-Ox (Fig. $4 \mathrm{~A}$ and $\mathrm{B})$. However, no changes in phosphorylation levels of AKT were observed. In addition, we did not detect any significant differences in phosphorylation levels of FGFR, ERK and protein expression of cyclin D1 between QGP-1 parental and RR cells (Fig. 4A and B).

We then investigated any potential oncogenic mutation accounting for the hyperactivation of these kinases. We performed genomic analysis on a list of genes as described in the 'Materials and methods' section (Supplementary Table 1). No additional mutations on any of these genes were found in QGP-1 R-Ox compared to parental cells, suggesting that hyperactivation of 'hit' kinases in QGP-1 $\mathrm{R}-\mathrm{Ox}$ is not due to characterized de novo oncogenic mutation. We also considered whether hyperactivation of these kinases could result from an overexpression of their corresponding genes. Transcriptomic analysis of a pan-cancer panel of 783 targets (Supplementary Table 2) showed that FGFR family mRNA were not significantly upregulated in either QGP-1 RR or QGP-1 R-Ox (Fig. 4C and Supplementary Table 2), implying that hyperactivation of FGFR kinases is not triggered by gene overexpression. However, a nearly two-fold significant increase in FGF2, MAPK1 and CCND1 mRNA levels were observed in QGP-1 $\mathrm{R}-\mathrm{Ox}$, accounting for an upregulation of the gene coding for FGF2, one of the FGFR ligands, as well as genes coding for ERK2 and cyclin D1 in these cells (Fig. 4C). These data suggests that FGFR hyperactivation in QGP-1 R-Ox cells likely results from a molecular mechanism affecting protein activity regulation.
Pharmacological inhibition of hyperactivated kinases in oxaliplatin-resistant QGP-1

\section{Effect of FGFR inhibition on downstream pathways and cell viability}

In order to challenge drug-resistant cells to a specific inhibition of FGFR signalling, we used the pan-FGFR inhibitor LY2874455 currently in phase 1. First, cell viability assay showed that QGP-1 R-Ox cells were more sensitive to FGFR inhibition than parental cells (Fig. 5A; $\mathrm{IC} 50=0.6 \pm 0.2 \mu \mathrm{M}, n=4$, in QGP-1 R-Ox; IC50 = 3.1 \pm 0.6 $\mu \mathrm{M}, n=5$, in QGP-1 parental, $P<0.01)$. As expected, chronic FGFR hyperphosphorylation in QGP-1 R-Ox cells was dose dependently decreased with the FGFR inhibitor (Fig. 5B and C). Moreover, although ERK phosphorylation was inhibited in QGP-1 parental, ERK hyperphosphorylation and cyclin D1 overexpression were progressively reduced in QGP-1 R-Ox in the presence of increasing doses of LY2874455 (Fig. 5B and C). PARP cleavage induced by LY2874455 was observed in both QGP-1 parental and R-Ox cells (Fig. 5B and D) after $48 \mathrm{~h}$ of treatment. However, PARP cleavage was more pronounced in R-Ox cells (Fig. 5B and D). These results suggest that cells undergo apoptosis upon FGFR inhibition.

\section{Effect of ERK pathway inhibition on cell viability}

Likewise, we investigated whether inhibition of MAPK ERK pathway affect QGP-1 R-Ox viability. Cell viability was progressively decreased in both QGP-1 parental and 

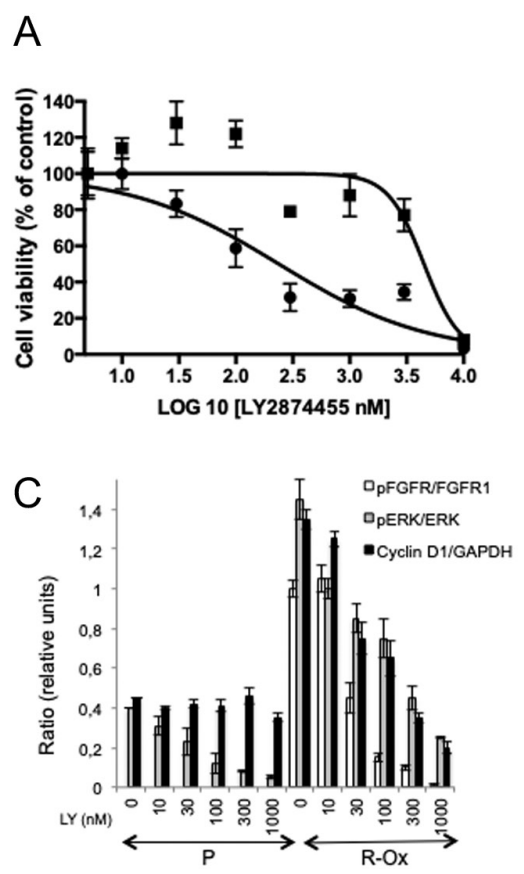
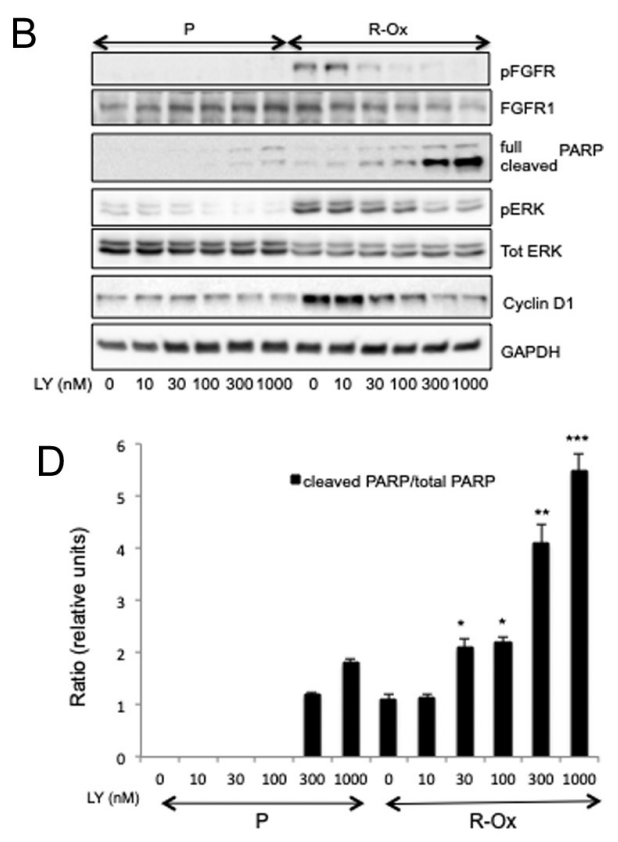

Figure 5

Selective sensitivity of QGP-1 R-Ox cells to FGFR inhibition. (A) QGP-1 parental (squares) and R-Ox (circles) were treated for 4 days with increasing concentrations of LY2874455 as indicated. Cell viability was assessed using Cell Titer Glo assay. A representative experiment is given. IC50 QGP-1 = $4.48 \mu \mathrm{M}$; IC50 QGP-1 R-Ox $=0.24 \mu \mathrm{M}$. (B) QGP-1 parental (P) and oxaliplatin-resistant (R-Ox) cells were treated $48 \mathrm{~h}$ with LY2874455 at the indicated dose. Ten micrograms of protein extracts were separated by SDS/PAGE and immunoprobed using pimary antibodies against indicated proteins. Membranes blotted with antibodies against phosphorylated proteins (pFGFR and pERK) were then stripped and re-probed using primary antibodies against total proteins. (C) Quantification of phosphorylated/ total proteins, cyclin D1/GAPDH and (D) cleaved PARP/full length PARP ratios expressed in relative values. Means \pm S.E.M. of $n=3$ experiments are shown. (C) pFGFR/FGFR, $P<0.05$ at $30 \mathrm{nM}$, $P<0.001$ from 100 to $1000 \mathrm{nM}$ vs control untreated QGP-1 R-Ox; pERK/ERK, $P<0.05$ at $100 \mathrm{nM}, P<0.01$ at 300 and $1000 \mathrm{nM}$ vs control untreated parental QGP-1; $P<0.05$ at 30 and $100 \mathrm{nM}, P<0.01$ at 300 and $1000 \mathrm{nM}$ vs control untreated QGP-1 R-Ox; cyclin D1/GAPDH, $P<0.05$ at 30 and $100 \mathrm{nM}, P<0.01$ at 300 and $1000 \mathrm{nM}$ vs control untreated QGP-1 R-Ox. (D) $* P<0.05$; $\star \star P<0.01 ; * \star * P<0.001$.
QGP-1 R-Ox in the presence of increasing doses of the MEK inhibitor trametinib. However no significant difference was observed between parental and oxaliplatin resistant cells (Fig. 6A; QGP-1 IC50=3.8 $\pm 1.3 \mathrm{nM}(n=3)$; QGP-1 $\mathrm{R}-\mathrm{OX}$ IC50 $=0.5 \pm 0.3 \mathrm{nM}(n=3) P>0.05)$. Whereas PARP cleavage was observed in QGP-1 parental at the highest dose of trametinib $(1 \mu \mathrm{M})$ only, PARP cleaved form was dose dependently increased in QGP-1 R-Ox (Fig. 6B and C). Cyclin D1 expression was progressively reduced by MEK inhibition in QGP-1 R-Ox only (Fig. 6B and C).

Taken together, these data suggest that activation of FGFR/ERK pathway is one of the potential signalling

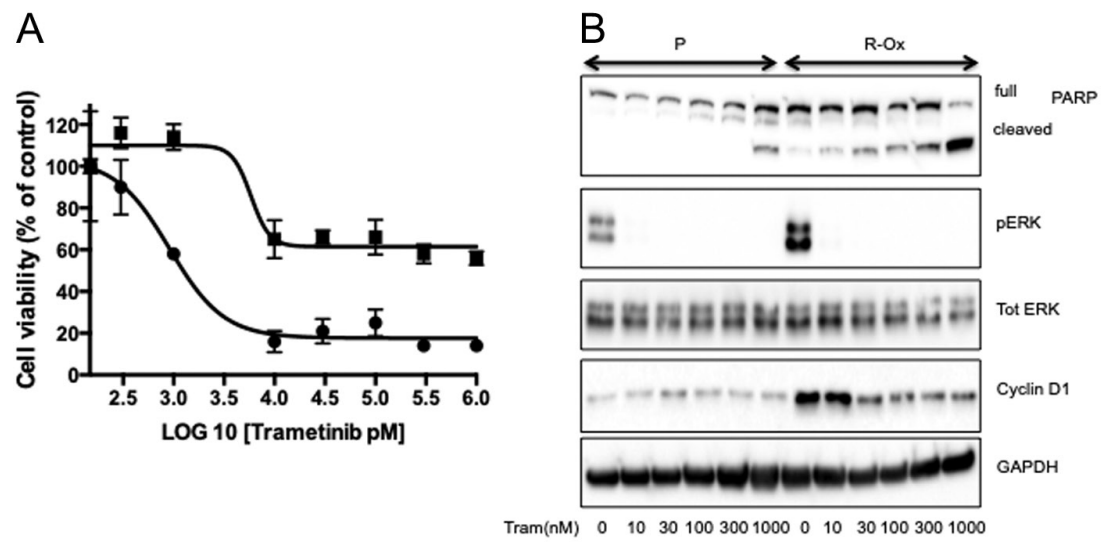

C

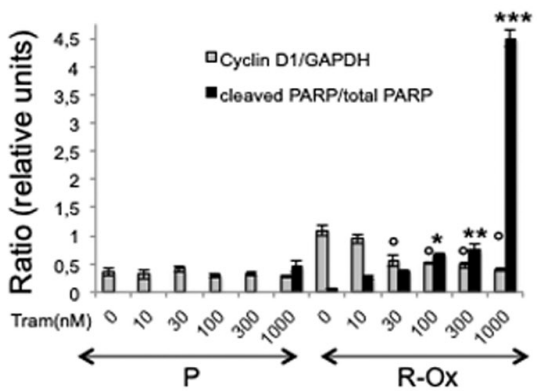

Figure 6

Selective sensitivity of QGP-1 R-ox cells to MEK inhibition. (A) QGP-1 parental (squares) and oxaliplatin-resistant (circles) were treated for 4 days with increasing concentrations of trametinib as indicated. Cell viability was assessed using Cell Titer Glo assay. A representative experiment is given. IC50 QGP-1 parental = $5.8 \mathrm{nM}$; IC50 QGP-1 R-Ox=0.9 nM. (B) QGP-1 parental (P) and oxaliplatin-resistant (R-Ox) cells were treated $48 \mathrm{~h}$ with trametinib at the indicated dose. In total, $10 \mu \mathrm{g}$ of protein extracts were separated by SDS/PAGE and immunoprobed using primary antibodies against indicated proteins. Membrane blotted with antibodies against phosphorylated ERK (PERK) was then stripped and reprobed using primary antibody against total ERK proteins. A representative experiment is given. (C) Quantification of cyclin D1/GAPDH and cleaved PARP/full length PARP expressed in relative values. Means \pm S.E.M. of $n=3$ experiments are shown. ${ }^{*} P<0.05 ; * \star P<0.01 ; * \star \star P<0.001$ vs control untreated QGP-1 R-Ox cells. 
aberrations involved in acquired resistance to oxaliplatinbased chemotherapy in NENs.

\section{Discussion}

Despite the variety of therapeutics options for treating NENs, most of these treatments results in tumour growth stabilization, followed by tumour progression. Therapeutic resistance is often the consequence of intracellular signalling networks rewiring governed by the catalytic activity of kinases (Fleuren et al. 2016). As such, kinases have recently been considered as bona fide markers of drug response in many cancers. We first used a functional microarray-based proteomics assay to investigate kinome profiles of NENs samples and NEN cell lines. With this approach, we studied kinome wide rewiring in acquired therapeutic resistance.

Tyrosine kinase activity is more often associated with mitogenicity, whereas Ser-/Thr-kinases are mostly involved in differentiated functions (Ardito et al. 2017). NEN samples (which are mainly well differentiated) clearly displayed lower Tyr-kinase and higher Ser/Thr-kinase activities than AdK samples, suggesting NENs signature in terms of kinase activity profiles (Supplementary Fig. 1). NENs cell lines also displayed lower Tyr-kinase and higher Ser/Thr-kinase kinomes activity profiles than both AdK samples and PDAC cell lines, with QGP-1 kinome profiles closer to AdK samples and PDCA cells. Altogether, these results confirmed that kinome activity correlates with the aggressive cellular phenotype (Supplementary Fig. 1). Finally, the comparison of NENs samples and NENs cell lines showed that BON-1 cells display a kinomic profile similar to G1/G2 well-differentiated NENs, whereas QGP-1 cells present with a kinomic profile close to the G3 poorly differentiated tumour sample in our study (Fig. $1)$. The differences observed between the Tyr-kinase and Ser/Thr-kinase kinomic profiles of BON-1 and QGP-1 may be correlated to previous works showing significant amounts of hormones secreted by BON-1 cells (Beauchamp et al. 1991), whereas, on the contrary, recent works suggested that QGP-1 cells may not be functioning (Luley et al. 2020). Thus, our kinome-wide functional proteomic approach emphasizes that NENs cell lines (i) possess kinomes recapitulating accurately NENs behaviour and (ii) present with a specific kinome activity signature distinct from carcinoma cells.

Although patients' stratification is beyond the scope of our study, we observed that NENs Tyr-kinome profiles classified according to their grade only (Fig. 1A), whereas
Ser-/Thr-kinome profiles were more homogeneous and prevented any statistically significant cluster (Fig. 1B). This observation is of interest considering that tumour grade provides critical information on the evolving patient profile. Further experiments expanding the cohort of samples to other neuroendocrine origins (e.g. bronchopulmonary, thyroid, etc.) would be necessary to acquire statistical robustness on the role of grading vs tissue of origin to sort NEN samples. In these conditions, kinome analysis would provide valuable opportunity to gain insights into identification of tumoural biomarkers and targets for therapeutic intervention through kinase inhibitors.

These results grounded the choice to investigate changes in kinomics profiles from NENs cell lines in drug resistance conditions. NENs cell lines drug sensitivity has largely been explored in order to identify potential therapeutic strategies for patients (Hofving et al. 2018). Yet, works aiming at studying drug resistance mechanisms in NENs are rare. For instance, novel mTor and dual PI3K/ mTor inhibitors were shown to potently overcome newly acquired everolimus resistance in BON-1 and QGP-1 cells (Vandamme et al. 2016). Similarly, GSK3 hyperactivation was also reported in everolimus-resistant BON-1 cells and selective inhibition of PI3K by BYL719 re-established everolimus sensitivity through GSK3 inhibition (Aristizabal Prada et al. 2018b). While establishing NENs cells sensitivity to everolimus and oxaliplatin, we observed that QGP-1 cells responded to both drugs, whereas BON-1 cells viability was affected by everolimus only in the same experimental conditions. These observations were in correlation with NENs cells kinomics profile, as QGP-1 cells appeared to behave like NEC and adenocarcinoma samples, proposing these cells as good candidates for treatment by cytotoxic chemotherapeutic agents. These findings offer the first opportunity to select a therapeutic option not only based on proliferation rate or mutational background, but on global kinome activity profile. In this study, we established everolimus-resistant QGP-1 cells and did not detect any significant differences in kinome profiles between parental and everolimus-resistant cells. These data suggest that resistance to mTor inhibition in QGP-1 cells does not involve specific kinase activation and occurs via different molecular mechanisms. Moreover, on the contrary to previous works describing increased in Akt signalling shortly after mTor inhibition (Missiaglia et al. 2010, Zitzmann et al. 2010, Passacantilli et al. 2014, Mohamed et al. 2017), we did not observe such activation in everolimus-resistant QGP-1. Our kinomics data were obtained from cells treated several months 
with everolimus. This difference in timelines could explain such discrepancy about Akt activity regulation. In addition, genomic screening failed to identify any additional mutations within wide cancer and NENs specific gene panels in everolimus-resistant QGP-1 cells compared to parental ones. These observations imply that acquisition of everolimus resistance in QGP-1 cells does not rely on further oncogenic addiction. However, a more comprehensive whole-genome comparative analysis may be required to search for potential driver mutations induced by chronic everolimus exposure.

Though chemotherapy-based therapeutic strategies are favoured for aggressive and poorly differentiated NENs, no models to study de novo resistance to chemotherapeutic agents were available to date. We obtained oxaliplatinresistant QGP-1, generating an original tool to study resistance mechanisms to cytotoxicity induced by chemotherapy in NENs. Comparative analysis of QGP-1 parental and oxaliplatin-resistant cells kinome profiles unveiled specific kinases hyperactivated in drug-resistant cells, notably FGFR family. FGFR signalling abnormalities in NENs have only been reported in isolated cases (Vranic et al. 2019). Here, we showed that FGFR kinase activity is specifically higher in 0xaliplatin-resistant cells. Genomic sequencing could not assign any wellknown constitutively active oncogenic mutations to such increased FGFR enzymatic activity. Also, FGFR mRNA levels were not significantly upregulated in oxaliplatin-resistant cells. These data suggest that FGFR kinase hyperactivation is more likely triggered by direct regulation at the protein level and could not be anticipated by genomic sequencing or gene expression profiling. Interestingly, we found increased FGF2 mRNA levels in QGP-1 R-Ox cells, suggesting a potential auto/ paracrine mechanism of FGFR re-activation in oxaliplatinresistant cells. Pharmacological inhibition of FGFR led to cell viability decrease. Downstream pathways recruited by FGFR activation include MAPK ERK and PI3K/AKT signalling cascades. In oxaliplatin-resistant QGP-1 cells, we only detected higher ERK phosphorylation in comparison with parental cells, highlighting a FGFR/ ERK axis selectively activated in oxaliplatin resistance conditions. Although QGP-1 R-Ox were at least six times more sensitive to MEK inhibition than parental cells, overall cell viability was not statistically significantly different. However, PARP cleavage was enhanced by either FGFR or MEK inhibition in QGP-1 R-Ox cells, unveiling the role of PARP as one of the mechanisms leading to sensitivity of drug-resistant cells to specific pharmacological inhibition of FGFR/ERK signalling pathway. This discrepancy between cell viability and apoptosis responses may reflect cell heterogeneity, in particular in oxaliplatin-resistant cells. Further analyses at single-cell levels are required to identify sub-clonal molecular mechanisms involved in acquired drug resistance. MAPK ERK signalling has previously been described as a hypothetical therapeutic target in NENs models (Zitzmann et al. 2010, Valentino et al. 2014). In our studies, we show that specific recruitment of MAPK ERK cascade may contribute to long-term resistance to chemotherapeutic-based treatment of NETs. As a consequence, this pathway, deregulated in many cancers, represents a novel prospective target for de novo chemoresistant NENs specimen.

Kinomics assay revealed hyperactivation of cyclindependent kinases (CDKs) in oxaliplatin-resistant cells. Inhibition of CDK4/6 was shown to decrease tumor cell proliferation in NENs cell lines and xenograft models (Aristizabal Prada et al. 2018a). Our study demonstrates that cyclin D1, a positive regulator of CDKs allowing entry into the S phase (Casimiro et al. 2014), is overexpressed in oxaliplatin-resistant QGP-1 cells, both at mRNA and protein levels. Therefore, CDK1/2/3 hyperactivation measured by kinomics assay in oxaliplatin-resistant cells may result from cyclin D1 overexpression. Interestingly, both FGFR and MEK inhibition led to a decrease in cyclin D1 expression in drug-resistant cells, suggesting a tight crosstalk between FGFR/ERK pathway and cell cycle regulation in oxaliplatin-resistant cells.

Altogether, our data provide novel insights in NENs biology and drug resistance. We used an emerging method to allow simultaneous and unbiased measurement of the activation state of the kinome. Additional complexities arise from the ability of microenvironmental factors to influence phosphorylation-dependent signalling and from the tendency for some signalling processes to occur heterogeneously among tumour cells. However, this approach conveyed to the discovery of aberrant signalling biomarkers involved in drug resistance conditions which were unsuspected by integrated genomics analysis.

Supplementary materials

This is linked to the online version of the paper at https://doi.org/10.1530/ ERC-19-0142.

\section{Declaration of interest}

The authors declare that there is no conflict of interest that could be perceived as prejudicing the impartiality of the research reported. 


\section{Funding}

The project leading to this publication has received institutional funding from INSERM (French Institute for Medical Research), from Excellence Initiative of Aix-Marseille University-A*Midex, a French 'Investissements d'Avenir' programme. This project also received grants from GEFLUC (French Entreprises against Cancer), 'Fondation ARC' (French Foundation for Cancer Research), ADEREM (Association for Medical Research), the Endocrine Tumour Group (GTE) the French Society of Endocrinology (SFE).

\section{Acknowledgement}

The authors thank Faris Naji (Pamgene) for BioNavigator software training.

\section{References}

Ardito F, Giuliani M, Perrone D, Troiano G \& Lo Muzio L 2017 The crucial role of protein phosphorylation in cell signaling and its use as targeted therapy (Review). International Journal of Molecular Medicine 40 271-280. (https://doi.org/10.3892/ijmm.2017.3036)

Aristizabal Prada ET \& Auernhammer CJ 2018 Targeted therapy of gastroenteropancreatic neuroendocrine tumours: preclinical strategies and future targets. Endocrine Connections 7 R1-R25. (https://doi.org/10.1530/EC-17-0286)

Aristizabal Prada ET, Nölting S, Spoettl G, Maurer J \& Auernhammer CJ $2018 a$ The novel cyclin-dependent kinase 4/6 inhibitor Ribociclib (LEE011) alone and in dual-targeting approaches demonstrates antitumoral efficacy in neuroendocrine tumors in vitro. Neuroendocrinology 106 58-73. (https://doi.org/10.1159/000463386)

Aristizabal Prada ET, Spöttl G, Maurer J, Lauseker M, Koziolek EJ, Schrader J, Grossman A, Pacak K, Beuschlein F, Auernhammer CJ, et al. 2018b The role of GSK3 and its reversal with GSK3 antagonism in everolimus resistance. Endocrine-Related Cancer 25 893-908. (https://doi.org/10.1530/ERC-18-0159)

Bajetta E, Catena L, Procopio G, De Dosso S, Bichisao E, Ferrari L, Martinetti A, Platania M, Verzoni E, Formisano B, et al. 2007 Are capecitabine and oxaliplatin (XELOX) suitable treatments for progressing low-grade and high-grade neuroendocrine tumours? Cancer Chemotherapy and Pharmacology 59 637-642. (https://doi. org/10.1007/s00280-006-0306-6)

Beauchamp RD, Coffey Jr RJ, Lyons RM, Perkett EA, Townsend Jr CM \& Moses HL 1991 Human carcinoid cell production of paracrine growth factors that can stimulate fibroblast and endothelial cell growth. Cancer Research 51 5253-5260.

Budde K, Zonnenberg BA, Frost M, Cheung W, Urva S, Brechenmacher T, Stein K, Chen D, Kingswood JC \& Bissler JJ 2016 Pharmacokinetics and pharmacodynamics of everolimus in patients with renal angiomyolipoma and tuberous sclerosis complex or lymphangioleiomyomatosis. British Journal of Clinical Pharmacology 81 958-970. (https://doi.org/10.1111/bcp.12834)

Casimiro MC, Velasco-Velázquez M, Aguirre-Alvarado C \& Pestell RG 2014 Overview of cyclins D1 function in cancer and the CDK inhibitor landscape: past and present. Expert Opinion on Investigational Drugs 23 295-304. (https://doi.org/10.1517/13543784.2014.867017)

Corbo V, Beghelli S, Bersani S, Antonello D, Talamini G, Brunelli M, Capelli P, Falconi M \& Scarpa A 2012 Pancreatic endocrine tumours: mutational and immunohistochemical survey of protein kinases reveals alterations in targetable kinases in cancer cell lines and rare primaries. Annals of Oncology 23 127-134. (https://doi.org/10.1093/ annonc/mdr048)

Di Florio A, Adesso L, Pedrotti S, Capurso G, Pilozzi E, Corbo V, Scarpa A, Geremia R, Delle Fave G \& Sette C 2011 Src kinase activity coordinates cell adhesion and spreading with activation of mammalian target of rapamycin in pancreatic endocrine tumour cells. Endocrine-Related Cancer 18 541-554. (https://doi.org/10.1530/ ERC-10-0153)

Dussol AS, Joly MO, Vercherat C, Forestier J, Hervieu V, Scoazec JY, Lombard-Bohas C \& Walter T 2015 Gemcitabine and oxaliplatin or alkylating agents for neuroendocrine tumors: comparison of efficacy and search for predictive factors guiding treatment choice. Cancer 121 3428-3434. (https://doi.org/10.1002/cncr.29517)

Faure M, Niccoli P, Autret A, Cavaglione G, Mineur L \& Raoul JL 2017 Systemic chemotherapy with FOLFOX in metastatic grade $1 / 2$ neuroendocrine cancer. Molecular and Clinical Oncology 6 44-48. (https://doi.org/10.3892/mco.2016.1097)

Fleuren ED, Zhang L, Wu J \& Daly RJ 2016 The kinome 'at large' in cancer. Nature Reviews: Cancer 16 83-98. (https://doi.org/10.1038/ nrc.2015.18)

Girardi DM, Silva ACB, Rêgo JFM, Coudry RA \& Riechelmann RP 2017 Unraveling molecular pathways of poorly differentiated neuroendocrine carcinomas of the gastroenteropancreatic system: a systematic review. Cancer Treatment Reviews 56 28-35. (https://doi. org/10.1016/j.ctrv.2017.04.002)

Graham MA, Lockwood GF, Greenslade D, Brienza S, Bayssas M \& Gamelin E 2000 Clinical pharmacokinetics of oxaliplatin: a critical review. Clinical Cancer Research 6 1205-1218.

Hadoux J, Malka D, Planchard D, Scoazec JY, Caramella C, Guigay J, Boige V, Leboulleux S, Burtin P, Berdelou A, et al. 2015 Post-first-line FOLFOX chemotherapy for grade 3 neuroendocrine carcinoma. Endocrine-Related Cancer 22 289-298. (https://doi.org/10.1530/ERC15-0075)

Hofving T, Arvidsson Y, Almobarak B, Inge L, Pfragner R, Persson M, Stenman G, Kristiansson E, Johanson V \& Nilsson O 2018 The neuroendocrine phenotype, genomic profile and therapeutic sensitivity of GEPNET cell lines. Endocrine-Related Cancer 25 367-380. (https://doi.org/10.1530/ERC-17-0445)

Inzani F, Petrone G \& Rindi G 2018 The New World Health Organization classification for pancreatic neuroendocrine neoplasia. Endocrinology and Metabolism Clinics of North America 47 463-470. (https://doi.org/10.1016/j.ecl.2018.04.008)

Jiao Y, Shi C, Edil BH, de Wilde RF, Klimstra DS, Maitra A, Schulick RD, Tang LH, Wolfgang CL, Choti MA, et al. 2011 DAXX/ATRX, MEN1, and mTOR pathway genes are frequently altered in pancreatic neuroendocrine tumors. Science 331 1199-1203. (https://doi. org/10.1126/science.1200609)

Kawasaki K, Fujii M \& Sato T 2018 Gastroenteropancreatic neuroendocrine neoplasms: genes, therapies and models. Disease Models and Mechanisms 11 dmm029595. (https://doi.org/10.1242/ dmm.029595)

Kidd M, Schimmack S, Lawrence B, Alaimo D \& Modlin IM 2013 EGFR/ TGF $\alpha$ and TGF $\beta / C T G F$ signaling in neuroendocrine neoplasia: theoretical therapeutic targets. Neuroendocrinology 97 35-44. (https:// doi.org/10.1159/000334891)

Klempner SJ, Gershenhorn B, Tran P, Lee TK, Erlander MG, Gowen K, Schrock AB, Morosini D, Ross JS, Miller VA, et al. 2016 BRAFV600E mutations in high-grade colorectal neuroendocrine tumors may predict responsiveness to BRAF-MEK combination therapy. Cancer Discovery 6 594-600. (https://doi.org/10.1158/2159-8290.CD-151192)

Konukiewitz B, Jesinghaus M, Steiger K, Schlitter AM, Kasajima A, Sipos B, Zamboni G, Weichert W, Pfarr N \& Klöppel G 2018 Pancreatic neuroendocrine carcinomas reveal a closer relationship to ductal adenocarcinomas than to neuroendocrine tumors G3. Human Pathology 77 70-79. (https://doi.org/10.1016/j. humpath.2018.03.018)

Kulke MH 2017 Novel treatment options for neuroendocrine tumors. Journal of the National Comprehensive Cancer Network 15 737-739. (https://doi.org/10.6004/jnccn.2017.0088) 
Luley KB, Biedermann SB, Künstner A, Busch H, Franzenburg S, Schrader J, Grabowski P, Wellner UF, Keck T, Brabant G, et al. 2020 A comprehensive molecular characterization of the pancreatic neuroendocrine tumor cell lines BON-1 and QGP-1. Cancers 12691. (https://doi.org/10.3390/cancers12030691)

Missiaglia E, Dalai I, Barbi S, Beghelli S, Falconi M, della Peruta M, Piemonti L, Capurso G, Di Florio A, delle Fave G, et al. 2010 Pancreatic endocrine tumors: expression profiling evidences a role for AKT-mTOR pathway. Journal of Clinical Oncology 28 245-255. (https://doi.org/10.1200/JCO.2008.21.5988)

Mohamed A, Romano D, Saveanu A, Roche C, Albertelli M, Barbieri F, Brue T, Niccoli P, Delpero JR, Garcia S, et al. 2017 Anti-proliferative and anti-secretory effects of everolimus on human pancreatic neuroendocrine tumors primary cultures: is there any benefit from combination with somatostatin analogs? Oncotarget 8 41044-41063. (https://doi.org/10.18632/oncotarget.17008)

Nölting S, Rentsch J, Freitag H, Detjen K, Briest F, Möbs M, Weissmann V, Siegmund B, Auernhammer CJ, Aristizabal Prada ET, et al. 2017 The selective PI3K $\alpha$ inhibitor BYL719 as a novel therapeutic option for neuroendocrine tumors: results from multiple cell line models. PLOS ONE 12 e0182852. (https://doi.org/10.1371/ journal.pone.0182852)

Ohmoto A, Rokutan H \& Yachida S 2017 Pancreatic neuroendocrine neoplasms: basic biology, current treatment strategies and prospects for the future. International Journal of Molecular Sciences 18143. (https://doi.org/10.3390/ijms18010143)

Passacantilli I, Capurso G, Archibugi L, Calabretta S, Caldarola S Loreni F, Delle Fave G \& Sette C 2014 Combined therapy with RAD001 e BEZ235 overcomes resistance of PET immortalized cell lines to mTOR inhibition. Oncotarget 5 5381-5391. (https://doi. org/10.18632/oncotarget.2111)

Pavel ME, Hainsworth JD, Baudin E, Peeters M, Hörsch D, Winkler RE, Klimovsky J, Lebwohl D, Jehl V, Wolin EM, et al. 2011 Everolimus plus octreotide long-acting repeatable for the treatment of advanced neuroendocrine tumours associated with carcinoid syndrome (RADIANT-2): a randomised, placebo-controlled, phase 3 study. Lancet 378 2005-2012. (https://doi.org/10.1016/S01406736(11)61742-X)

Pavel M, O'Toole D, Costa F, Capdevila J, Gross D, Kianmanesh R, Krenning E, Knigge U, Salazar R, Pape UF, et al. 2016 Enets consensus guidelines update for the management of distant metastatic disease of intestinal, pancreatic, bronchial neuroendocrine neoplasms (NEN) and NEN of unknown primary site. Neuroendocrinology 103 172-185. (https://doi.org/10.1159/000443167)

Qian ZR, Ter-Minassian M, Chan JA, Imamura Y, Hooshmand SM, Kuchiba A, Morikawa T, Brais LK, Daskalova A, Heafield R, et al. 2013 Prognostic significance of MTOR pathway component expression in neuroendocrine tumors. Journal of Clinical Oncology $\mathbf{3 1}$ 3418-3425. (https://doi.org/10.1200/JCO.2012.46.6946)

Riddell IA \& Lippard SJ 2018 Cisplatin and oxaliplatin: our current understanding of their actions. Metal Ions in Life Sciences 18 1-42. (https://doi.org/10.1515/9783110470734-001)

Scarpa A, Chang DK, Nones K, Corbo V, Patch AM, Bailey P, Lawlor RT, Johns AL, Miller DK, Mafficini A, et al. 2017 Whole-genome landscape of pancreatic neuroendocrine tumours. Nature 543 65-71. (https://doi.org/10.1038/nature21063)

Shamir ER, Devine WP, Pekmezci M, Umetsu SE, Krings G, Federman S, Cho SJ, Saunders TA, Jen KY, Bergsland E, et al. 2019 Identification of high-risk human papillomavirus and $\mathrm{Rb} / \mathrm{E} 2 \mathrm{~F}$ pathway genomic alterations in mutually exclusive subsets of colorectal neuroendocrine carcinoma. Modern Pathology 32 290-305. (https:// doi.org/10.1038/s41379-018-0131-6)

Simbolo M, Vicentini C, Mafficini A, Fassan M, Pedron S, Corbo V, Mastracci L, Rusev B, Pedrazzani C, Landoni L, et al. 2018 Mutational and copy number asset of primary sporadic neuroendocrine tumors of the small intestine. Virchows Archiv $\mathbf{4 7 3}$ 709-717. (https://doi.org/10.1007/s00428-018-2450-x)

Spada F, Antonuzzo L, Marconcini R, Radice D, Antonuzzo A, Ricci S, Di Costanzo F, Fontana A, Gelsomino F, Luppi G, et al. 2016 Oxaliplatin-based chemotherapy in advanced neuroendocrine tumors: clinical outcomes and preliminary correlation with biological factors. Neuroendocrinology 103 806-814. (https://doi. org/10.1159/000444087)

Valentino JD, Li J, Zaytseva YY, Mustain WC, Elliott VA, Kim JT, Harris JW, Campbell K, Weiss H, Wang C, et al. 2014 Cotargeting the PI3K and RAS pathways for the treatment of neuroendocrine tumors. Clinical Cancer Research 20 1212-1222. (https://doi. org/10.1158/1078-0432.CCR-13-1897)

Vandamme T, Beyens M, de Beeck KO, Dogan F, van Koetsveld PM, Pauwels P, Mortier G, Vangestel C, de Herder W, Van Camp G, et al. 2016 Long-term acquired everolimus resistance in pancreatic neuroendocrine tumours can be overcome with novel PI3K-AKTmTOR inhibitors. British Journal of Cancer 114 650-658. (https://doi. org/10.1038/bjc.2016.25)

Vranic S, Palazzo J, Sanati S, Florento E, Contreras E, Xiu J, Swensen J \& Gatalica Z 2019 Potential novel therapy targets in neuroendocrine carcinomas of the breast. Clinical Breast Cancer 19 131-136. (https:// doi.org/10.1016/j.clbc.2018.09.001)

Wilson LJ, Linley A, Hammond DE, Hood FE, Coulson JM, MacEwan DJ, Ross SJ, Slupsky JR, Smith PD, Eyers PA, et al. 2018 New perspectives, opportunities, and challenges in exploring the human protein kinome. Cancer Research 78 15-29. (https://doi.org/10.1158/00085472.CAN-17-2291)

Xu C, Nezami Ranjbar MR, Wu Z, DiCarlo J \& Wang Y 2017 Detecting very low allele fraction variants using targeted DNA sequencing and a novel molecular barcode-aware variant caller. BMC Genomics 185. (https://doi.org/10.1186/s12864-016-3425-4)

Yao JC, Fazio N, Singh S, Buzzoni R, Carnaghi C, Wolin E, Tomasek J, Raderer M, Lahner H, Voi M, et al. 2016 Everolimus for the treatment of advanced, non-functional neuroendocrine tumours of the lung or gastrointestinal tract (RADIANT-4): a randomised, placebo-controlled, phase 3 study. Lancet 387 968-977. (https://doi. org/10.1016/S0140-6736(15)00817-X)

Zitzmann K, Rüden Jv, Brand S, Göke B, Lichtl J, Spöttl G \& Auernhammer CJ 2010 Compensatory activation of Akt in response to mTOR and Raf inhibitors - a rationale for dual-targeted therapy approaches in neuroendocrine tumor disease. Cancer Letters 295 100-109. (https://doi.org/10.1016/j.canlet.2010.02.018) 